\title{
MUTATIONS OF THE TYROSINASE GENE IN THREE KOREAN PATIENTS WITH TYPE I OCULOCUTANEOUS ALBINISM
}

\author{
Kyoung Chan Park, ,** Sang Kyu Park, ${ }^{2}$ Yong Suk LeE, ${ }^{1}$ \\ Sang Woong Youn, ${ }^{1}$ Byung Soon PARK, ${ }^{1}$ Kyu Han Kim, ${ }^{1}$ \\ and Seung Taek LEE ${ }^{2}$ \\ ${ }^{1}$ Department of Dermatology, Seoul National University College of Medicine, \\ Seoul 110-744, Korea \\ ${ }^{2}$ Department of Biochemistry, College of Science, and Bioproduct Research Center, \\ Yonsei University, Seoul 110-744, Korea
}

\begin{abstract}
Summary Oculocutaneous albinism (OCA) is an inherited disorder of the melanin pigmentary system, characterized by a decrease or an absence of melanin in the skin, hair, and eyes. Type I (tyrosinase-deficient) OCA results from mutations of the tyrosinase (TYR) gene encoding tyrosinase, the enzyme that catalyzes at least the first two steps of melanin biosynthesis. We have analyzed the $T Y R$ gene in three Korean patients with severe type I OCA. Two patients were compound heterozygotes for the $\mathrm{Arg}(\mathrm{CGG})$ to $\mathrm{Gln}$ (CAG) mutation at position 77 and a $\mathrm{C}$ insertion mutation at position 310 . The other was a compound heterozygote for a $\mathrm{C}$ insertion mutation at position 310 and the Asp (GAT) to Asn (AAT) mutation at position 383. These mutations were easily detected by restriction enzyme digestion or by SSCP analysis. Such methods of mutation analysis thus provide a basis for a screening system for the $T Y R$ gene mutations in Korean patients with type I OCA.
\end{abstract}

Key Words oculocutaneous albinism, tyrosinase, mutations, Korean

\section{INTRODUCTION}

Albinism is a heterogeneous group of heritable disorders, characterized by reduced or absent melanin pigmentation. Albinism is classified into two forms; oculocutaneous albinism (OCA) in which the melanin deficiency involves the skin, hair, and eyes (King and Summers, 1988), and ocular albinism (OA) in which the defect is confined mainly to the visual system (Witkop, 1989). Type I (tyro sinase-deficient) OCA results from deficient catalytic activity of tyrosinase. Tyro-

Received March 7, 1996; Revised version accepted May 21, 1996.

* To whom correspondence should be addressed: Department of Dermatology, Seoul National University Hospital, 28 Yongon-dong, Chongno-gu, Seoul 110-744, Korea. 
sinase (EC 1.14.18.1) is a copper-containing enzyme responsible for at least the first two steps in the melanin biosynthetic pathway: the conversion of tyrosine to dihydroxyphenylalanine (DOPA) and of DOPA to dopaquinone (Pomeranz, 1966; Korner and Pawelek, 1982). The phenotype of type I OCA varies from a complete absence of melanin synthesis to almost normal levels of cutaneous pigment formation (Oetting and King, 1994). Recent development of molecular genetic techniques has led to a greatly improved understanding of the molecular pathogenesis of type I OCA. To date, more than 50 different mutations of the tyrosinase $(T Y R)$ gene have been reported in patients with type I OCA (Oetting and King, 1994). However, the vast majority of these patients were Caucasians. We show here the presence of three mutant alleles of the $T Y R$ gene in three Korean patients with severe type I OCA.

\section{MATERIALS AND METHODS}

Patients. Three unrelated Korean patients had typical features of severe type I (tyrosinase-negative) OCA showing no apparent pigmentation in skin and hair, and decreased visual acuity. The patients were a 2-year-old female, a 14-year-old female, and a 1-year-old male.

Polymerase chain reaction (PCR) amplification, single-strand conformation polymorphism (SSCP) analysis, and direct dideoxy chain termination sequencing. The genomic DNA was extracted by methods previously described (Park et al., 1993). DNA segments corresponding to each of five exons of the tyrosinase gene were amplified from the genomic DNA of the patients and their family members by using PCR with primers prepared according to the $T Y R$ gene sequence published previously (Table 1) (Saiki et al., 1988; Giebel et al., 1991). PCR products of each exon were screened for the presence of mutations by SSCP analysis (Orita et al., 1989). SSCP analysis was followed by using the MDE gel method (AT Biochem). A $0.5 \times \mathrm{MDE}$ gel, in $0.6 \times \mathrm{TBE}$, was prepared. Three to 5 $\mu 1$ of PCR products were mixed with the same volume of loading buffer $(95 \%$ formamide, $10 \mathrm{mM} \mathrm{NaOH}, 20 \mathrm{mM}$ EDT A, $0.02 \%$ bromophenol blue), denatured at

Table 1. Primer pairs used to amplify $T Y R$ exon segment.

\begin{tabular}{cl}
\hline Exon & \multicolumn{1}{c}{ PCR primer } \\
\hline 1 & 5' TAAGATAAAGACTAAAAGTG $3^{\prime}$ \\
2 & 5' TTATACCCTGCCTGAAGAAG $3^{\prime}$ \\
& 5' CTCAGGAGAAGTCTAACAAC $3^{\prime}$ \\
3 & 5' AACTCAGAAATTCTGAATTC $3^{\prime}$ \\
4 & 5' GAGTCTCAATACGGAATGAA $3^{\prime}$ \\
& 5' TTTAAATCCAATGAGCACGT $3^{\prime}$ \\
5 & 5' TTAATATATGCCTTATTTTA $3^{\prime}$ \\
& 5' TAAAGTTTTGTGTATCTCA $3^{\prime}$ \\
& 5' TCCAAAGGAACTGTGAAAGG $3^{\prime}$ \\
\hline
\end{tabular}


$95^{\circ} \mathrm{C}$, and loaded onto the gel immediately. After loading the sample, electrophoresis was performed at $4^{\circ} \mathrm{C}$. After electrophoresis, the gel was soaked in $0.1 \%$ silver nitrate solution for $10 \mathrm{~min}$ and rinsed with distilled water. The gel was then soaked in $1.5 \% \mathrm{NaOH}, 0.15 \%$ formaldehyde for $10 \mathrm{~min}$ for visualization.

Exon PCR products which showed aberrant SSCP pattern were directly sequenced using the dideoxy chain termination method (Sanger et al., 1977).

Restriction fragment length polymorphism. The PCR products of exon 1 were amplified with two primers (5'-CTCCGCTGGCCATTTCCCTA-3', $5^{\prime}$ GGTGCTTCATGGGCAAAATC-3') from patient 1 and her mother, patient 2, and one unrelated normal Korean. These fragments were tested by digestion with HpaII and polyacrylamide gel electrophoresis.

\section{RESULTS}

Patient 1 was a compound heterozygote for two different mutations. One mutation was a base substitution of $\mathrm{G}$ to $\mathrm{A}$ within exon 1 resulting in a missense mutation of codon $77 \mathrm{Arg}$ (CGG) to Gln (CAG) (R77Q). Because R77Q mutation removes a HpaII restriction endonuclease site (CCGG to CCAG), the HpaII digestion of exon 1 PCR products could easily identify the R77Q mutation. By the HpaII digestion, we showed that the $\mathrm{R} 77 \mathrm{Q}$ mutation of patient 1 was inherited from her mother (Fig. 1). The other mutation of patient 1 was a $\mathrm{C}$ insertion mutation at codon 310 Pro, CCA to CCCA (P310insC) within exon 2. The $\mathrm{P} 310$ ins $\mathrm{C}$ mutation results in a premature termination of the translation of tyrosinase.

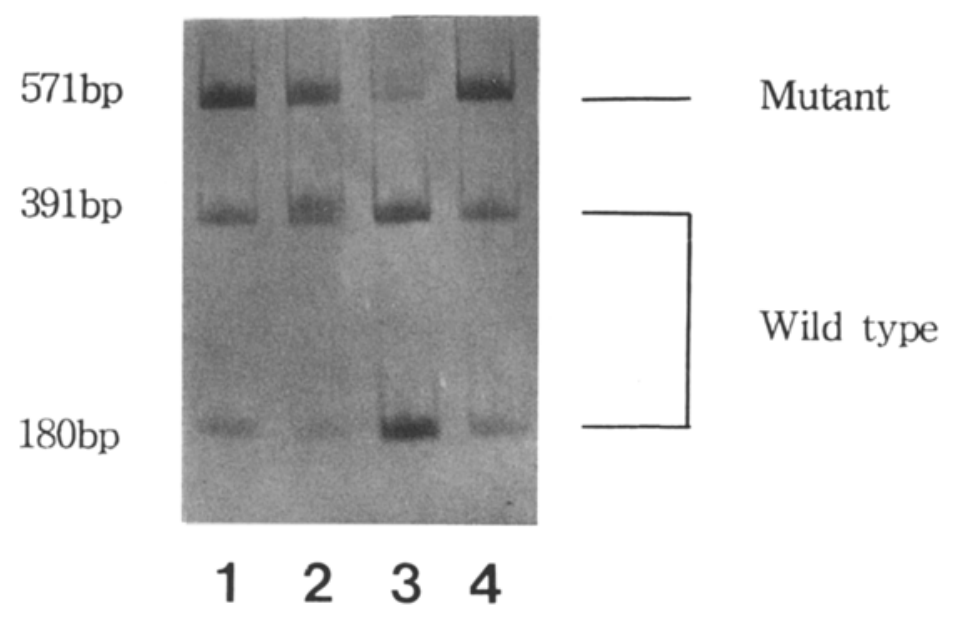

Fig. 1. HpaII RFLP analysis of exon 1 PCR products from patient 1 and her mother, a normal individual, and patient 2. The $\mathrm{R} 77 \mathrm{Q}$ mutation eliminates a HpaII site. The exon 1 PCR product derived from normal individual (lane 3) contained the HpaII site whereas patient 1 (lane 1), her mother (lane 2), and the patient 2 (lane 4) were heterozygous for the HpaII polymorphism. 
Patient 2 was a compound heterozygote for the two mutations found in the patient 1 . The $\mathrm{R} 77 \mathrm{Q}$ and $\mathrm{P} 310 \mathrm{ins} \mathrm{C}$ mutations of patient 2 were readily detected by SSCP analysis and HpaII digestion of exon 1 PCR product (Fig. 1) and by DNA sequence determination of exon 2 PCR product, respectively.
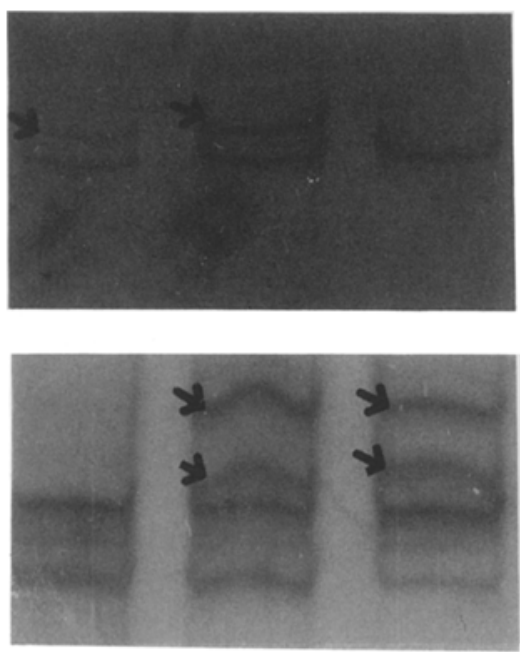

\section{Exon III}

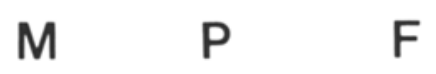

Fig. 2. The PCR products of exons 2 and 3 amplified from patient 3 and his family members were analyzed by SSCP. M: mother, P: patient, F: father. Mutant allele appeared as shifted bands (arrow).

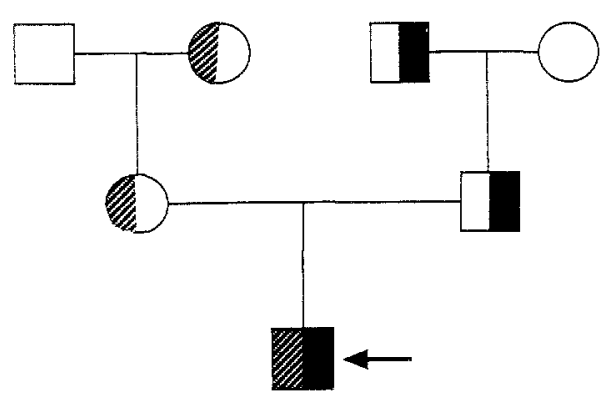

Fig. 3. Pedigree of the tyrosinase mutations in the families of the patient 3. The arrow indicates the patient. Circles denote women, and squares denote men. The shaded symbols indicate alleles with the P310insC mutation in exon 2 and the blackened symbols indicate alleles with the D383N mutation in exon 3. Results show that the mutant allele (D383N) in exon 3 was inherited from the father and the mutant allele in exon 2 (P310insC) from the mother. 
Patient 3 was a compound heterozygote for the P310insC mutation and another mutation. The 2 nd mutation was a base substitution of $G$ to $A$ within exon 3 which resulted in a missense mutation of codon 383 Asp (GAT) to Asn (AAT) (D383N).

To analyze the segregation of mutant alleles in the family of patient 3 , the patient and members of his family were subjected to SSCP analysis with the PCR products of exons 2 and 3 (Fig. 2). Patient 3 had both mutations within exon 2 (P310insC) and exon 3 (D383N), but none of unaffected family members had both mutations. The mutant allele of exon 2 was inherited from his maternal grandmother and the mutant allele of exon 3 from his paternal grandfather (Fig. 3).

\section{DISCUSSION}

We have analyzed the $T Y R$ gene in three Korean patients with severe type I OCA. All patients studied here had a typical phenotype of severe type I OCA, with no apparent pigmentation in skin and hair, and decreased visual acuity. In this study, we found three different TYR mutations: R77Q, P310insC, and D383N. The $\mathrm{R} 77 \mathrm{Q}$ mutation and P310insC mutation have been reported only in Japanese patients with severe type I OCA (Tomita et al., 1989; Takeda et al., 1990) (Table 2). From our results, we speculate that Koreans may have some ethnic overlap with Japanese. However, the D383N mutation found in patient 3 has been identified in Caucasians relatively frequently (frequency: -0.04) (Spritz, 1994). Historically, there is no apparent connection between Koreans and Caucasians and thus it is possible that the D383N mutation in Caucasians has been introduced into the Korean population. However, we cannot exclude the possibility that the D383N mutation found in patient 3 may be a recurrent mutation.

Tyrosinase is a copper-containing enzyme responsible for the conversion of tyrosine to DOPA and of DOPA to dopaquinone and plays a central role in melanin biosynthesis. It has been reported that the missense mutations associated with severe type I OCA cluster in four distinct areas of the tyrosinase-coding region (Oetting and King, 1994). These clusters are thought to represent important functional domains of the enzyme necessary for catalytic activity and, therefore, would be sensitive to amino acid substitutions. Two of the clusters are the putative

Table 2. Published mutations of the TYR gene associated with oculocutaneous albinism in Orientals.

\begin{tabular}{llccl}
\hline Mutation & \multicolumn{1}{c}{ Base substitution } & OCA type & Population & \multicolumn{1}{c}{ Reference } \\
\hline R77Q & CGG $($ Arg $) \rightarrow$ CAG $(\mathrm{Gln})$ & IA & Japanese & Takeda et al., 1990 \\
& & & Korean & This report \\
L288delT & TTA (Leu) $\rightarrow$ TA & IA & Korean & Spritz, 1994 \\
P310insC & CCA (Pro) $\rightarrow$ CCCA & IA & $\begin{array}{l}\text { Japanese } \\
\text { Tomita } \text { et al., 1989 }\end{array}$ \\
D383N & GAT (Asp) $\rightarrow$ AAT (Asn) & IA & Korean & This report \\
\hline
\end{tabular}

Vol. 41, No. 3, 1996 
copper A and copper B binding sites. The third cluster is a N-terminal domain of tyrosinase and the fourth cluster is at the $3^{r}$ end of the copper B binding region (Oetting and King, 1994). These latter two clusters are thought to be substrate and/ or co-factor binding sites or may be involved in enzyme stability. The R77Q and D383N mutations are pathologic because these mutations are located in the third cluster and the copper B binding site, respectively. The $\mathrm{P} 310 \mathrm{ins} \mathrm{C}$ mutation seems to be pathologic because this mutation results in premature termination of translation of tyrosinase by a frame shift. Furthermore, the R77Q and P310insC have been shown to be defective by transient expression assays (Tomita et al., 1989; Takeda et al., 1990).

When a specific mutation changes a restriction enzyme site, the presence of the mutation is easily identified by restriction enzyme digestion of the exon PCR products from patients and their family members. In case that a specific mutation does not change any restriction enzyme site, SSCP analysis can then be applied to detect the presence of the specific mutation in patients and their family members. We have shown that patients 1 and 2 are heterozygous for the R77Q mutation and that the mother of patient 1 was a carrier by HpaII digestion of exon 1 PCR product. In addition, the P310insC and D383N mutations were readily identified by characteristic SSCP patterns of the patients and their families. These analytic methods used here will be useful to screen for the mutations in Korean patients with severe OCA I and to detect carriers of the mutations.

Acknowledgments This work was supported by a grant from the Genetic Engineering Research Fund of the Ministry of Education of Korea (1994).

\section{REFERENCES}

Giebel LB, Strunk KM, Spritz RA (1991): Organization and nucleotide sequences of the human tyrosinase gene and a truncated tyrosinase-related segment. Genomics 9: 1-11

King RA, Summers CG (1988): Albinism. Dermatol Clin 6: 217-228

Korner AM, Pawelek JM (1982): Mammalian tyrosinase catalyzes three reactions in the biosynthesis of melanin. Science 217: 1163-1165

Oetting WS, King RA (1994): Analysis of tyrosinase mutations associated with tyrosinase-related oculocutaneous albinism (OCA 1). Pigm Cell Res 7: 285-290

Orita M, Iwahana H, Kanazawa H, Hayashi K, Seika T (1989): Detection of polymorphism of human DNA by gel electrophoresis as single-strand conformation polymorphism. Proc Nat1 Acad Sci USA 86: 2766-2770

Park KC, Chintamaneni CD, Halaban R, Witkop CJ Jr, Kwon BS (1993): Molecular analysis of a tyrosinase-negative albino family. Am J Hum Genet 52: 406-413

Pomeranz SH (1966): Tyrosine hydroxylase activity of mammalian tyrosinase. J Biol Chem 241: $161-168$

Saiki RK, Gelfand DH, Stoffel S, Scharf SJ, Higuchi R, Horn GT, Mullis KB, Erlich HA (1988): Primer-directed enzymatic amplification of DNA with a thermostable DNA polymerase. Science 239: 487-491

Sanger F, Nicklen S, Coulson AR (1977): DNA sequencing with chain-terminating inhibitors. Proc Natl Acad Sci USA 74: 5463-5467

Spritz RA (1994): Molecular genetics of oculocutaneous albinism. Hum Mol Genet 3: 1469-1475

Jpn J Human Genet 
Takeda A, Tomita Y, Matsunaga J, Tagami H, Shibahara S (1990): Molecular basis of tyrosinasenegative oculocutaneous albinism. J Biol Chem 265: 17792-17797

Tomita Y, Takeda A, Okinaga S, Tagami H, Shibahara S (1989): Human oculocutaneous albinism caused by single base insertion in the tyrosinase gene. Biochem Biophys Res Commun 164: 990-996

Witkop CJ Jr (1989): Albinism. Clin Dermatol 7: 80-91

Vol. 41, No. 3, 1996 